\title{
Pharmacological Modulation of Mucosa-Related Impairment of $\beta$-Adrenoceptor-Mediated Relaxation in Human Detrusor
}

\author{
Stefan Propping ${ }^{a, b} \quad$ Melanie Roedel $^{a} \quad$ Manfred P. Wirth ${ }^{b} \quad$ Ursula Ravens $^{a}$

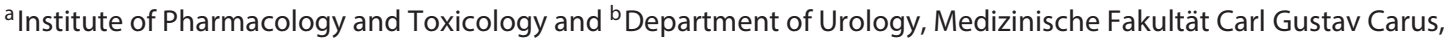 \\ Technische Universität Dresden, Dresden, Germany
}

\section{Key Words}

Detrusor smooth muscle · Relaxation · Urothelium - Mucosa · $\beta$-Adrenoceptors · Signal transduction

\begin{abstract}
Objectives: The mucosa of human detrusor strips impairs catecholamine-induced relaxation. In order to elucidate which signal transduction pathways are involved in this cross talk between the mucosa and detrusor, we have studied the effects of several pharmacological agonists and antagonists on noradrenaline-mediated relaxation in intact and mucosa-denuded detrusor strips. Patients and Methods: Strips of detrusor tissue were obtained from patients who had undergone cystectomy for bladder cancer and were set up for force measurement. $\mathrm{KCl}$ - or carbachol-precontracted strips were relaxed with increasing concentrations of noradrenaline in the absence and in the presence of nitric oxide synthase inhibitor, L-NAME; P2X-receptor antagonist, $\mathrm{PPADS} ; \mathrm{ET}_{\mathrm{A}}$-receptor antagonist, $\mathrm{BQ}-123 ; \mathrm{ET}_{\mathrm{B}}$-receptor antagonist, BQ-788; cyclooxygenase inhibitor, diclofenac; $\mathrm{AT}_{1}$-receptor antagonist, candesartan; and $\mathrm{NK}_{1}$-receptor antagonist, L-703,606. Results: In intact strips, KCl-stimulated force was enhanced by all blockers; carbachol-stimulated force increased with $L-703,606$. In denuded strips, only L-NAME augmented the KCl-stimulated contraction. Noradrenaline relaxed the precontracted detrusor strips to a sig-
\end{abstract}

nificantly larger extent and at lower concentrations in denuded than in intact strips. L-NAME, PPADS and BQ-123/ BQ-788 had little effect on noradrenaline-induced relaxation, whereas diclofenac, candesartan and L-703,606 sensitized intact carbachol-stimulated detrusor strips to noradrenaline-induced relaxation. Conclusion: Inhibition of the noradrenaline-induced relaxation of precontracted human detrusor strips by the mucosa is attenuated by diclofenac, candesartan and L-703,606 suggesting the involvement of prostanoids, angiotensin and neurokinin pathways. Further experiments are required to unravel the exact mechanisms.

(c) 2015 S. Karger AG, Basel

\section{Introduction}

Antimuscarinic drugs are the mainstay for the treatment of overactive bladder symptoms, and tolerability of side effects may be improved by combining selective and unselective agents [1]. Whether the recently introduced $\beta_{3}$-adrenoceptor $\left(\beta_{3}\right.$-AR) agonist, mirabegron [2], will provide better long-term results has to await further experience. Future drugs may even target the modulatory role of the urothelium on urinary bladder contractility.

In ex vivo experiments, the mucosa of the human urinary bladder provides significant inhibitory effects on de-

\section{KARGER 125}

(c) 2015 S. Karger AG, Base

$0042-1138 / 15 / 0953-0300 \$ 39.50 / 0$ 
trusor contractions in response to various modes of stimulation, for example, muscarinic agonists [3-7], tachykinins [8] or electric field stimulation $[9,10]$. Conflicting results were reported for contractions elicited by $\mathrm{KCl}$ depolarization, the urothelium having been associated with either a robust effect [7] or no effect at all [9]. In particular, the differences between denuded and intact detrusor strips faded during steady-state force development [6]. Upon stimulation, the mucosa apparently releases a diffusible factor, the 'urothelium-derived relaxing factor' $[4,6]$.

Precontracted human detrusor relaxes in response to catecholamines, and this effect is mediated via $\beta$-ARs of the $\beta_{3}$-AR subtype $[11,12]$. As reported previously [6], noradrenaline relaxed the precontracted detrusor strips in a concentration-dependent manner, and relaxation was significantly larger and required lower concentrations in denuded than in intact strips. Therefore, the mucosa also affects catecholamine-induced relaxation of human detrusor, but in the opposite direction as expected from the release of an 'urothelium-derived relaxing factor'. In other words, the mucosa impairs relaxation. This study and those by others have shown recently that isoprenaline and noradrenaline are less effective in relaxing carbachol-precontracted intact detrusor strips than mucosa-denuded muscles, suggesting that the mucosa could also be associated with a 'contracting factor' in addition to the 'relaxing factor' described previously $[6,13,14]$. The reduced sensitivity and efficacy of catecholamines for relaxing human detrusor muscles in the presence of mucosa was mediated via $\beta_{2}$-ARs $[6,15]$. These effects are highly species dependent, because mouse detrusor muscle relaxes mainly via $\beta_{2}$-AR $[15$, 16].

Previous efforts to unravel the nature of the 'urothelium-derived relaxing factors' have excluded the involvement of nitric oxide (NO), cyclooxygenase products, purinergic $\mathrm{P} 2 \mathrm{Y}$ receptors, TEA-sensitive $\mathrm{K}^{+}$channels and small $\mathrm{Ca}^{2+}$-activated $\mathrm{K}^{+}$channels $[4,9]$. However, which signal transduction pathways contribute to the mucosainduced impairment of relaxation remains unknown.

Stimulation of the mucosa with $\mathrm{KCl}$, carbachol and catecholamines could release signaling molecules which would in turn modulate contraction. The aim of our present study was to identify some of these signaling molecules by using selective pharmacological receptor agonists and/or antagonists. Because of the analogy between 'urothelium-derived relaxing factor' and 'endotheliumderived relaxing factor', drugs that are expected to affect vascular smooth muscles were chosen, including NO syn- thase inhibitor, L-NAME; P2X-receptor antagonist, PPADS; $\mathrm{ET}_{\mathrm{A}}$-receptor antagonist, $\mathrm{BQ}-123$; $\mathrm{ET}_{\mathrm{B}}$-receptor antagonist, BQ-788; cyclooxygenase inhibitor, diclofenac; $\mathrm{AT}_{1}$-receptor antagonist, candesartan; and $\mathrm{NK}_{1}$-receptor antagonist, L-703,606.

\section{Patients and Methods}

All patients donating tissue gave fully informed consent in accordance with the Declaration of Helsinki and the regulation of the local ethics committee (approval No. EK 194092004). Specimens of human detrusor muscle were obtained from the bladder dome of patients undergoing primary radical cystectomy for the treatment of carcinoma invading bladder muscle. Patients who had received chemotherapy or radiotherapy were excluded. The mean age of the 52 patients ( 32 male and 20 female) was $71 \pm$ 1 years.

\section{Preparation of Human Detrusor Strips}

Care was taken, that the muscle strips were obtained from tissue free of macroscopic tumor or inflammation. The tissue was transported in buffer solution to the laboratory within 15-30 min after excision. After careful removal of the serosa, 4-8 longitudinal muscle strips (10-15 mm length and 4-6 mm width) were cut from the tissue. The mucosa was removed from one-half of the preparations, but remained intact in the other half.

\section{Histological Studies}

Tissue samples were fixed in $4 \%$ buffered formalin. Samples were embedded in paraffin and cut in 4 - $\mu$ m-thick sections. The tissue was dewaxed in xylene and rehydrated in water through descending graded alcohols. The slides were incubated with hematoxylin for $3 \mathrm{~min}$ and then washed in tap water for $5 \mathrm{~min}$. The eosin staining was performed for $1 \mathrm{~min}$; the slides were then washed short in water. After that, the slides were dehydrated in ascending graded alcohols, washed 3 times in xylene and covered.

\section{Recording of Contractions}

All preparations were mounted in 5-ml organ baths containing carbogen-gassed Tyrode's solution at $37^{\circ} \mathrm{C}$. Isometric tension was measured with an isometric force transducer (GM 2, Föhr Medical Instruments, Seeheim/Ober-Beerbach, Germany), amplified and recorded with Chart 4.0 $0^{\mathrm{TM}}$ (ADInstruments, Sydney, Australia). Resting load was $10 \mathrm{mN}$. All experiments were carried out in the presence of the A-AR antagonists, phentolamine $(3 \mu \mathrm{M})$ and prazosin $(1 \mu \mathrm{M})$, to inhibit any AR-mediated processes.

During an equilibration period of $60 \mathrm{~min}$, the bath solution was changed 3 times. The detrusor strips were exposed to $40 \mathrm{mM} \mathrm{KCl}$ for $10 \mathrm{~min}$ followed by washout. Muscle strips were precontracted with $1 \mu \mathrm{M}$ carbachol or $40 \mathrm{mM} \mathrm{KCl}$, and responses became stable within $45 \mathrm{~min}$. Detrusor contraction was measured as force and expressed as $\mathrm{mN} / \mathrm{mg}$ wet weight of each muscle strip. Relaxation was then induced by stepwise increase of the concentration of (-)-noradrenaline, until a maximum was reached. All relaxations were expressed as percentage of maximum relaxation achieved with $10 \mu \mathrm{M}$ forskolin at the end of each experiment. Catecholamine-induced relaxation was either measured without any extra 

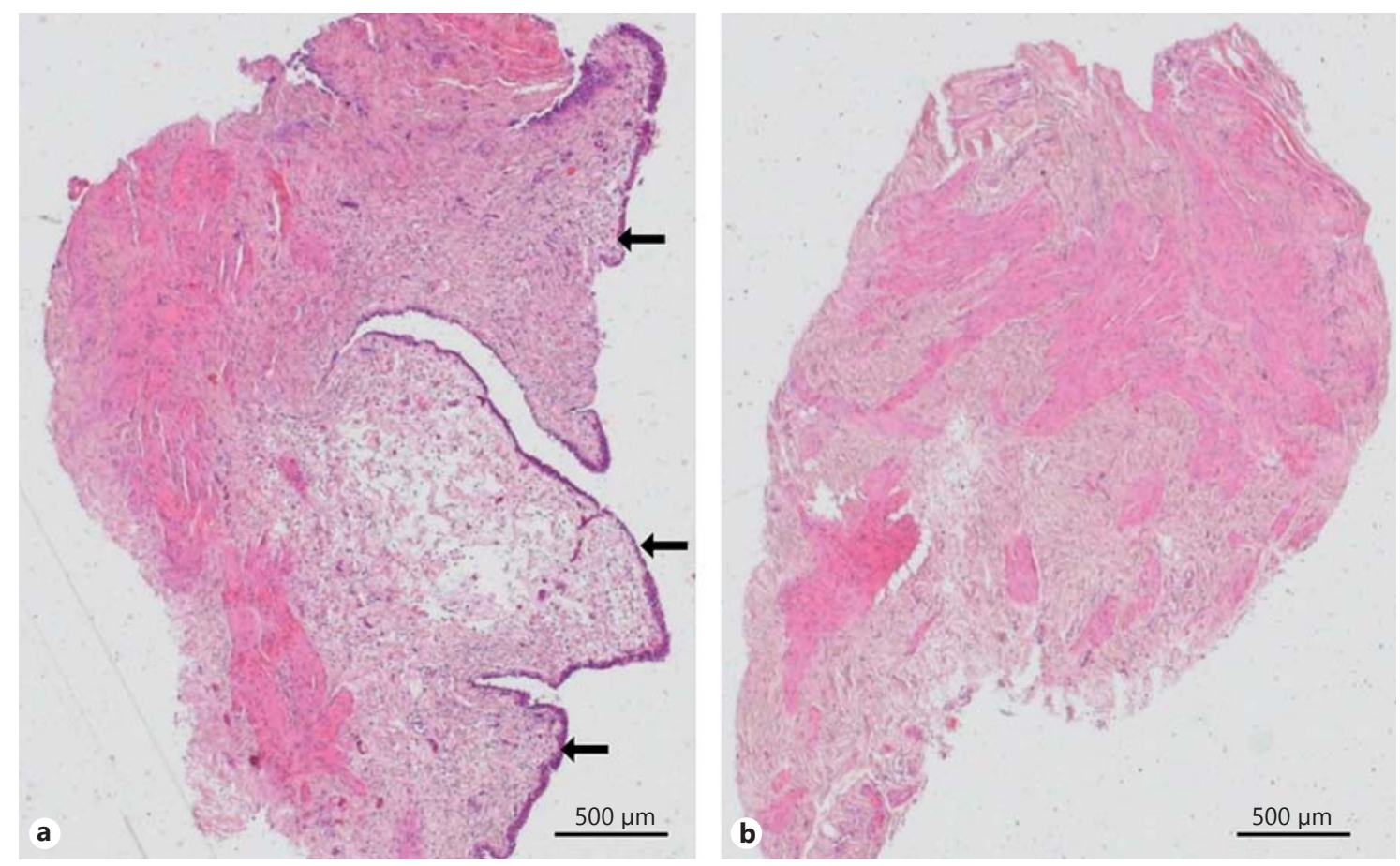

Fig. 1. Histological section of human detrusor strips with intact (a) and denuded urothelium (b). Arrows point at urothelium. Hematoxylin-eosin staining; scale bar $200 \mu \mathrm{m}$.

substance in the bath (time-matched controls) or in the presence of either one of the following modulators of signaling pathways - NO synthase inhibitor, L-NAME; P2X-receptor antagonist, PPADS; $\mathrm{ET}_{\mathrm{A}}$-receptor antagonist, $\mathrm{BQ}-123 ; \mathrm{ET}_{\mathrm{B}}$-receptor antagonist, BQ-788; cyclooxygenase inhibitor, diclofenac; $\mathrm{AT}_{1}$-receptor antagonist, candesartan; and $\mathrm{NK}_{1}$-receptor antagonist, L-703,606 added $45 \mathrm{~min}$ before catecholamine-induced relaxation.

\section{Drugs and Solutions}

The modified Ringer's solution contained (in $\mathrm{mM}$ ) $149 \mathrm{NaCl}$, $2.7 \mathrm{KCl}, 1.8 \mathrm{CaCl}_{2}, 0.1 \mathrm{NaH}_{2} \mathrm{HPO}_{4}$ and 5.6 glucose. The Tyrode's solution contained (in $\mathrm{mM}$ ) $127 \mathrm{NaCl}, 5.4 \mathrm{KCl}, 1.05 \mathrm{MgCl}_{2}, 1.8$ $\mathrm{CaCl}_{2}, 0.4 \mathrm{NaH}_{2} \mathrm{HPO}_{4}, 22 \mathrm{NaCO}_{3}, 0.04$ EDTA, 0.2 ascorbic acid and 5.6 glucose, $\mathrm{pH} 7.4$, when equilibrated with $95 \% \mathrm{O}_{2}$ and $5 \%$ $\mathrm{CO}_{2}$. Drugs and chemicals were obtained from Sigma (St. Louis, USA) and Tocris Bioscience (Bristol, UK). All drugs were dissolved in Milli-Q water (Millipore, Billerica, Mass., USA), with the exception of (-)-noradrenaline, which were dissolved in water containing $200 \mathrm{~mm}$ ascorbic acid and $40 \mathrm{mM}$ EDTA. Forskolin was dissolved in dimethyl sulfoxide, and stock solutions were further diluted with Milli-Q water.

\section{Data Analysis and Statistics}

Concentration-response curves for catecholamines were analyzed by nonlinear regression of each individual experiment using GraphPad 4.0 (GraphPad Prism Software Inc., San Diego, USA). The negative logarithm of the molar concentration producing $50 \%$ of the maximum relaxing effect $\left(-\log \mathrm{E}_{50}\right)$ was calculated. Results are presented as mean $-\log \mathrm{EC}_{50}$ values \pm SEM for 'n' muscle strips. Statistical differences were evaluated by using the Student's t test (paired or unpaired) and the analysis of variance. A value of $\mathrm{p}<0.05$ was considered statistically significant. Control experiments without addition of any drug were carried out for 2 projects that were done in parallel, that is, for our report identifying the $\beta$-AR subtype that was involved [6] and for the present one.

\section{Results}

Human intact and mucosa-denuded detrusor strips were histologically controlled for complete removal of the urothelium. Denuded strips were devoid of any urothelium which stains with hematoxylin-eosin as a continuous dark pink cell layer in intact strips (arrows in fig. 1).

Activation of intact and mucosa-denuded human detrusor strips with $40 \mathrm{mM} \mathrm{KCl}$ or $1 \mu \mathrm{M}$ carbachol yielded the typical transient increase in force of contraction that declined to a constant level within $45 \mathrm{~min}$ (inset in fig. 2), with significantly less peak force of contraction upon either mode of stimulation in intact strips than denuded strips [6]. Preincubation of the preparations with the selective test drugs to block various receptors and enzymes resulted in the following responses (fig. 2). (1) Peak and 


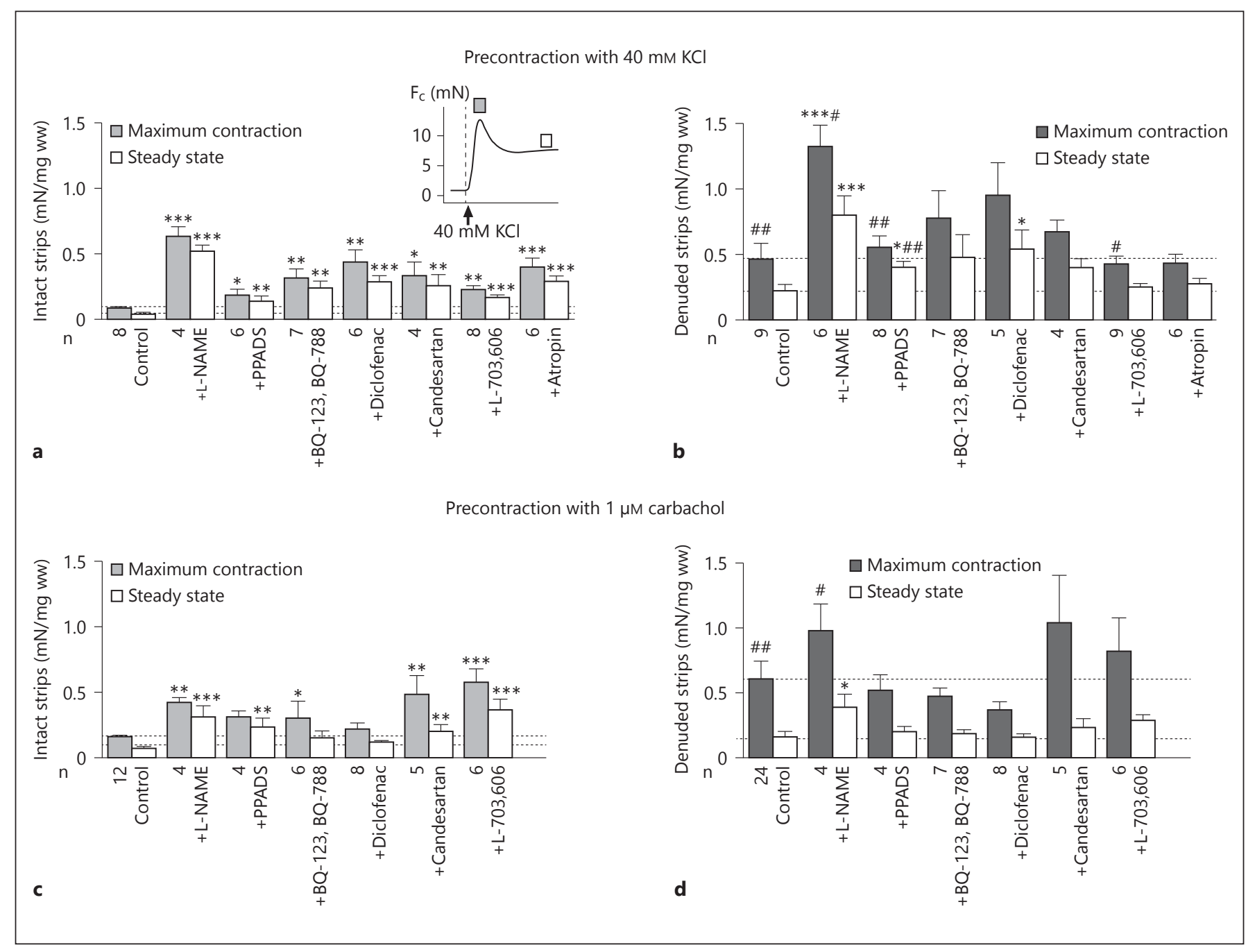

Fig. 2. Peak and steady-state force of contraction of human detrusor strips after stimulation (inset). Stimulation with $\mathrm{KCl}(40 \mathrm{mM})$ in $\mathbf{a}$ and $\mathbf{b}$, with carbachol $(1 \mu \mathrm{M})$ in $\mathbf{c}$ and $\mathbf{d}$, intact strips in $\mathbf{a}$ and $\mathbf{c}$ and mucosa-denuded strips in $\mathbf{b}$ and $\mathbf{d}$. Preparations were studied under control conditions and in the presence of various drugs.

steady-state force with $\mathrm{KCl}$ were enhanced by all blockers in intact strips and by L-NAME only in denuded strips. In addition, PPADS and diclofenac also increased steadystate force in the latter. (2) Like in controls, KCl-stimulated force was significantly lower in intact than in denuded preparation after preincubation with L-NAME, PPADS and L-703,606. (3) Carbachol-induced force in intact strips increased in the presence of the blockers with the exception of diclofenac, but none of the test compounds affected the peak force of denuded strips.

Control noradrenaline-induced relaxation of precontracted detrusor strips was described previously as being

Pharmacological Modulation of Mucosa-Related Impairment
Force of contraction is given in $\mathrm{mN} / \mathrm{mg}$ wet weight. Means \pm SEM from $\mathrm{n}=$ number of investigated patients. ${ }^{*} \mathrm{p}<0.05$, ${ }^{* *} \mathrm{p}<0.01$, ${ }^{* * *} \mathrm{p}<0.001$ compared with control force without any drug; ${ }^{\#} \mathrm{p}<$ 0.05 , ${ }^{\# \#} \mathrm{p}<0.01$ denuded versus intact strips.

significantly larger and requiring lower concentrations in denuded than in intact strips [6]. These control data are used also in the present study (fig. 3; table 1 [6], with permission of the publisher). Pretreatment with L-NAME neither affected the sensitivity of the relaxation response to noradrenaline $\left(-\log \mathrm{EC}_{50}\right.$ values in table 1$)$, nor the difference between denuded and intact detrusor, although the maximum effect expressed in percentage of relaxation elicited by $10 \mu \mathrm{M}$ forskolin ( $\mathrm{E}_{\max }$ in table 1 ) was slightly, but significantly, larger after L-NAME pretreatment (intact strips stimulated with carbachol only; fig. 3). The P2X-receptor blocker, PPADS, decreased sensitivity for noradren- 


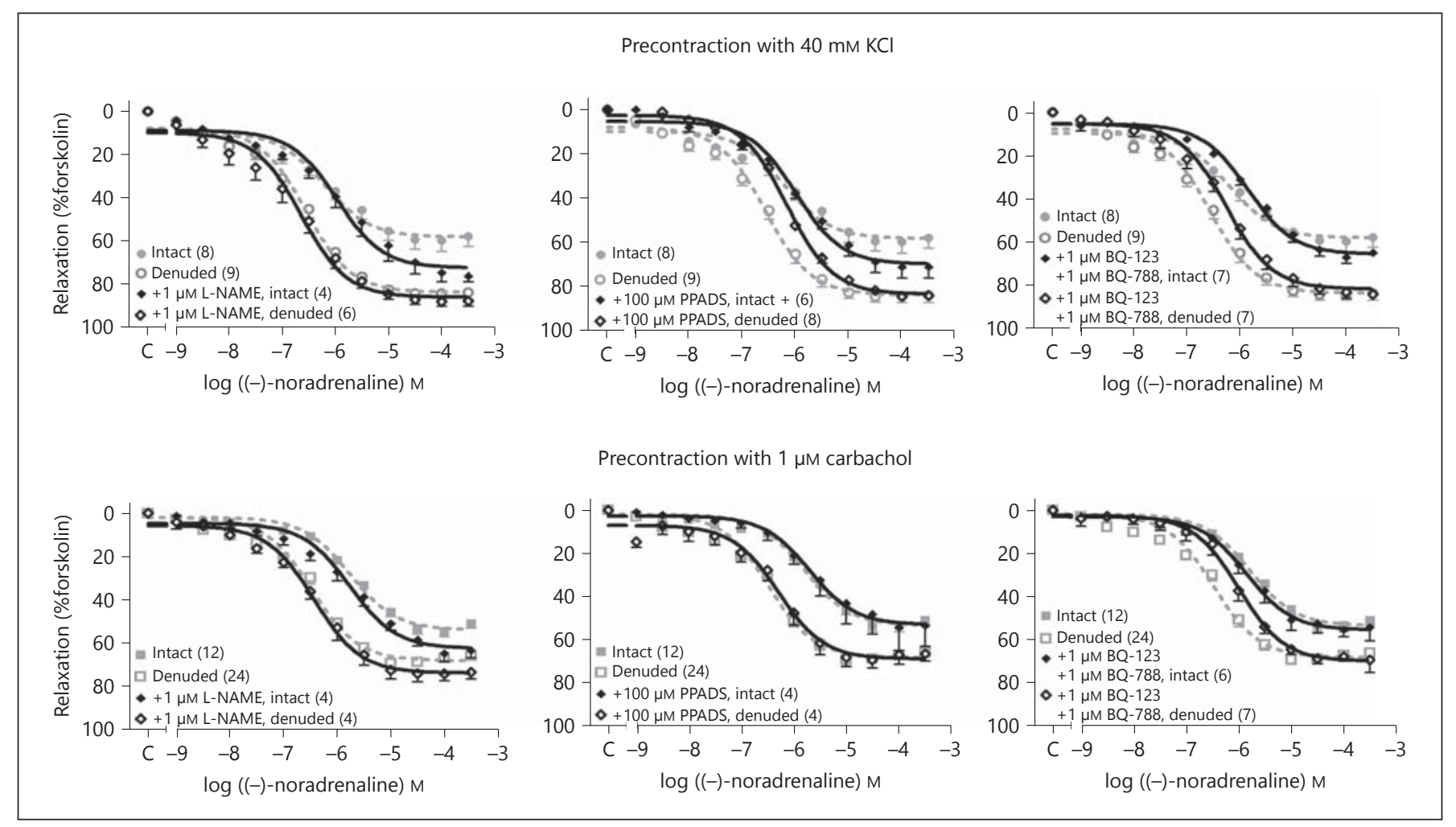

Fig. 3. Concentration-response curves for the relaxing effects of (-)-noradrenaline on $\mathrm{KCl}$ - and carbachol-induced contractions (upper and lower row, respectively) in human intact or mucosadenuded detrusor strips. Control conditions (gray symbols, dashed lines) and in the presence of drug (black symbols, continuous lines), i.e. L-NAME, $1 \mathrm{mM}$; PPADS, $100 \mu \mathrm{M}$; and BQ-123/BQ-788, $1 \mu \mathrm{M}$. Data are expressed in $\%$ of maximum relaxation induced by $10 \mu \mathrm{M}$ forskolin $(=100 \%)$. Mean \pm SEM from ' $n$ ' investigated strips (numbers in parenthesis).

Table 1. Relaxing effects of noradrenaline in human detrusor strips with intact and denuded urothelium and their modulation by various drugs

\begin{tabular}{|c|c|c|c|c|c|c|c|}
\hline \multirow[t]{2}{*}{ Precontraction } & \multirow[t]{2}{*}{ Additional drug } & \multicolumn{3}{|c|}{ Intact urothelium } & \multicolumn{3}{|c|}{ Denuded urothelium } \\
\hline & & $-\log \mathrm{EC}_{50}[\mathrm{M}]$ & $\mathrm{E}_{\max }[\%]$ & $\mathrm{n}$ & $-\log \mathrm{EC}_{50}[\mathrm{M}]$ & $\mathrm{E}_{\max }[\%]$ & $\mathrm{n}$ \\
\hline \multirow[t]{8}{*}{$\mathrm{KCl}, 40 \mathrm{mM}$} & None $(\text { control })^{1}$ & $6.20 \pm 0.07$ & $58 \pm 3$ & 8 & $6.57 \pm 0.08^{\# \#}$ & $84 \pm 3^{\# \# \#}$ & 9 \\
\hline & L-NAME, $1 \mu \mathrm{M}$ & $5.90 \pm 0.20$ & $74 \pm 3^{*}$ & 4 & $6.72 \pm 0.17$ & $86 \pm 2$ & 6 \\
\hline & PPADS, $100 \mu \mathrm{M}$ & $6.04 \pm 0.04$ & $66 \pm 5$ & 6 & $6.17 \pm 0.04^{* * *}$ & $83 \pm 1$ & 8 \\
\hline & BQ-123, $1 \mathrm{mM}$; BQ-788, $1 \mathrm{~mm}$ & $5.83 \pm 0.08^{* *}$ & $66 \pm 3$ & 7 & $6.27 \pm 0.10^{*}$ & $82 \pm 3$ & 7 \\
\hline & Diclofenac, $100 \mu \mathrm{M}$ & $6.65 \pm 0.21^{*}$ & $85 \pm 2^{* * *}$ & 6 & $7.11 \pm 0.12^{* *}$ & $85 \pm 3$ & 5 \\
\hline & Candesartan, $100 \mu \mathrm{M}$ & $6.23 \pm 0.09$ & $78 \pm 6^{*}$ & 4 & $6.77 \pm 0.15$ & $85 \pm 3$ & 4 \\
\hline & $\mathrm{L}-703,606,1 \mu \mathrm{M}$ & $6.02 \pm 0.22$ & $61 \pm 4$ & 8 & $6.63 \pm 0.29$ & $72 \pm 4^{*}$ & 9 \\
\hline & Atropine, $1 \mu \mathrm{M}$ & $6.20 \pm 0.12$ & $64 \pm 4$ & 6 & $6.68 \pm 0.06$ & $86 \pm 2$ & 6 \\
\hline \multirow[t]{7}{*}{ Carbachol, $1 \mu \mathrm{M}$} & None (control) ${ }^{1}$ & $5.76 \pm 0.06$ & $55 \pm 3$ & 12 & $6.41 \pm 0.09^{\# \# \#}$ & $70 \pm 3^{\# \# \#}$ & 24 \\
\hline & L-NAME, $1 \mu \mathrm{M}$ & $5.78 \pm 0.16$ & $74 \pm 4^{* *}$ & 4 & $6.43 \pm 0.08$ & $63 \pm 3$ & 4 \\
\hline & PPADS, $100 \mu \mathrm{M}$ & $5.68 \pm 0.11$ & $54 \pm 11$ & 4 & $6.31 \pm 0.10$ & $69 \pm 4$ & 4 \\
\hline & BQ-123, $1 \mathrm{mM}$; BQ-788, $1 \mathrm{~mm}$ & $5.81 \pm 0.10$ & $56 \pm 4$ & 6 & $6.05 \pm 0.13^{*}$ & $71 \pm 2$ & 7 \\
\hline & Diclofenac, $100 \mu \mathrm{M}$ & $6.20 \pm 0.15^{* *}$ & $71 \pm 4^{* *}$ & 8 & $6.66 \pm 0.0^{*}$ & $77 \pm 3^{*}$ & 8 \\
\hline & Candesartan, $100 \mu \mathrm{M}$ & $6.56 \pm 0.13^{* * *}$ & $76 \pm 5^{* *}$ & 5 & $7.02 \pm 0.08^{* * *}$ & $85 \pm 2 * *$ & 5 \\
\hline & $\mathrm{L}-703,606,1 \mu \mathrm{M}$ & $6.11 \pm 0.11^{*}$ & $75 \pm 4^{* * *}$ & 6 & $6.40 \pm 0.09$ & $83 \pm 2^{* *}$ & 6 \\
\hline
\end{tabular}

Precontraction by $\mathrm{KCl}$ or carbachol. $\mathrm{E}_{\max }=$ Maximum response in \% of response to $10 \mu \mathrm{M}$ forskolin $(=100 \%)$; $\mathrm{n}=$ number of detrusor strips.

Comparison between intact and denuded urothelium: ${ }^{\# \#} \mathrm{p}<0.01$, \#\#\# $\mathrm{p}<0.001$. Comparison with respective control (no extra drug added): ${ }^{*} \mathrm{p}<0.05$, ${ }^{* *} \mathrm{p}<0.01,{ }^{* * *} \mathrm{p}<0.001 .{ }^{1}$ Values taken from [4]. 


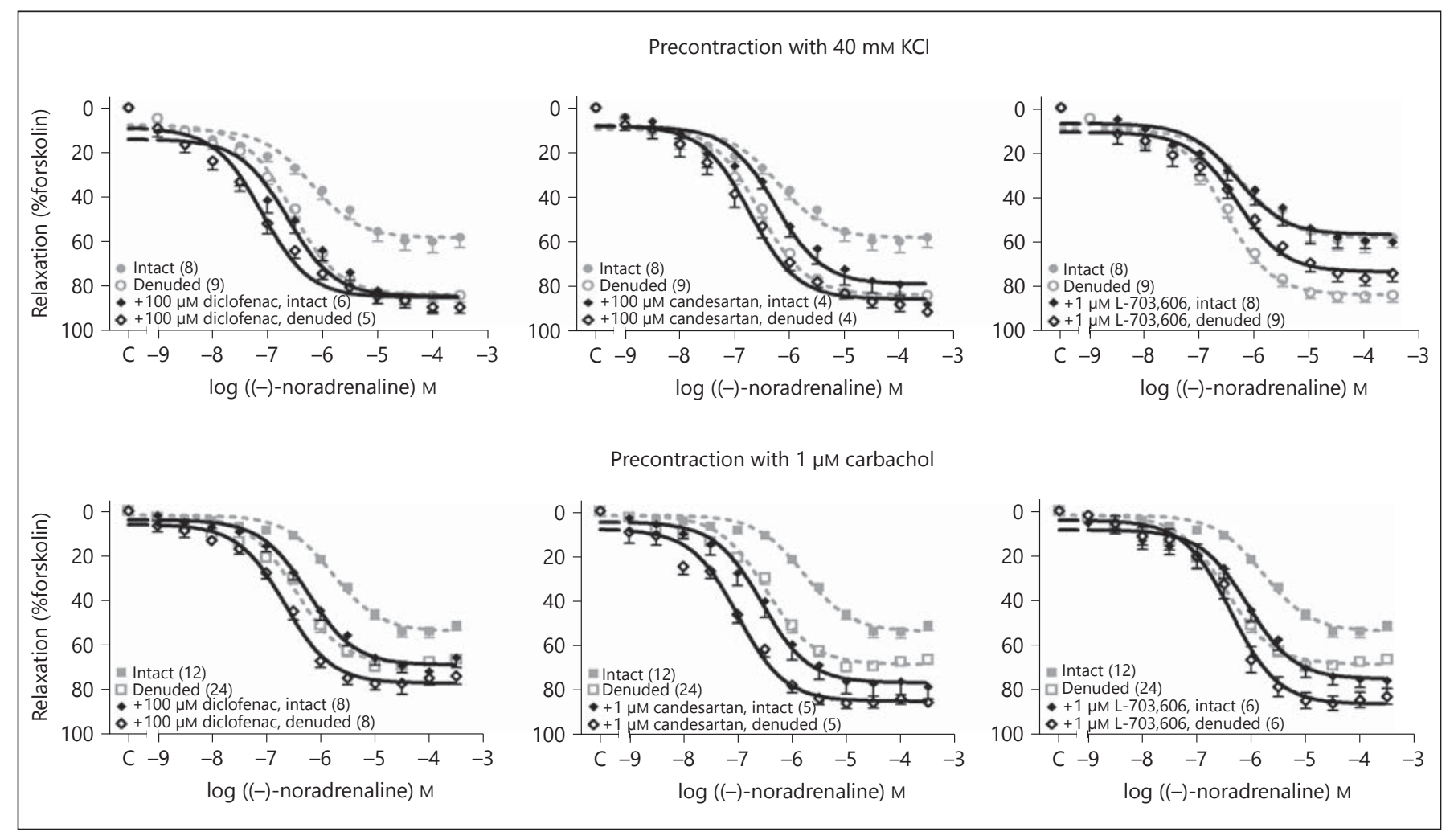

Fig. 4. Concentration-response curves for the relaxing effects of (-)-noradrenaline on $\mathrm{KCl}$ - and carbachol-induced contractions (upper and lower row, respectively) in human intact or mucosadenuded detrusor. Control conditions (gray symbols, dashed lines) and in the presence of drug (black symbols, continuous

aline-relaxation only in denuded, $\mathrm{KCl}$-depolarized muscle strips, thereby reducing the difference between intact and denuded preparations, but not in carbachol-stimulated strips. Block of $\mathrm{ET}_{\mathrm{A}^{-}}$and $\mathrm{ET}_{\mathrm{B}}$-receptors with $\mathrm{BQ}-123 / \mathrm{BQ}-$ 788 shifted the concentration-response curves to higher concentrations of noradrenaline without affecting the extent of relaxation. The difference between intact and denuded strips was maintained in $\mathrm{KCl}$-stimulated but reduced in carbachol-stimulated muscles. In the presence of diclofenac (fig. 4), noradrenaline relaxed intact detrusor muscles to the same extent as denuded preparations and with similar potency as in control-denuded strips. In addition diclofenac-pretreated, denuded strips also became more sensitive to noradrenaline. Modulation of relaxation by diclofenac was similar in $\mathrm{KCl}$ - and carbachol-stimulated muscles. Candesartan, however, produced similar effects as that of diclofenac on sensitivity to, and efficacy of, noradrenaline in carbachol-stimulated strips; with $\mathrm{KCl}$ precontraction, the only diclofenac effect was enhancement of $\mathrm{E}_{\max }$ in intact strips. The $\mathrm{NK}_{1}$-receptor blocker, L-703,606, however, re-

Pharmacological Modulation of Mucosa-Related Impairment lines), i.e. diclofenac, $100 \mu \mathrm{M}$; candesartan, $100 \mu \mathrm{M}$; and L-703,606, $1 \mu \mathrm{M}$. Data are expressed in \% of maximum relaxation induced by $10 \mu \mathrm{M}$ forskolin $(=100 \%)$. Mean \pm SEM from ' $n$ ' investigated strips (numbers in parenthesis).

duced sensitivity to noradrenaline in $\mathrm{KCl}$-precontracted denuded muscles, but increased sensitivity in both intact and denuded carbachol-stimulated preparations.

\section{Discussion}

In the present study, we have investigated the influence of various pharmacological agonists and antagonists on mucosa relaxation induced with (-)-noradrenaline in human $\mathrm{KCl}$ - or carbachol-precontracted detrusor smooth muscles. Our major findings were the following: (1) Although NO signaling counteracts $\mathrm{KCl}$ contractions, it does not appear to be involved in mediating the specific mucosa effects on relaxation. (2) Inhibition of cyclooxygenase abolishes the mucosa effect on (-)-noradrenalineinduced relaxation in $\mathrm{KCl}$ - and carbachol-precontracted muscles. (3) AT1 receptor blocker, candesartan, and $\mathrm{NK}_{1}$-receptor blocker, L-703,606, have similar effects, but only in carbachol-stimulated strips. 


\section{Urothelium versus Mucosa}

Upon stretch, the urothelium releases active compounds, such as non-neuronal acetylcholine [17], ATP [18], tachikinins [19] and prostaglandins [20], that can either directly activate detrusor contraction or indirectly modulate contractility via stimulation of suburothelial nerves.

The histological sections in figure 1 clearly show complete removal of the urothelium; however, we cannot distinguish whether the urothelium alone or the whole mucosa is responsible for the observed differences between intact and denuded muscle strips. Human urothelial cell lines express various functional G-protein coupled receptors that are involved in the release of further signaling molecules $[21,22]$. These findings suggest that urothelial cells themselves could be the source of 'urothelium-derived factors' causing either relaxation or blunting of relaxant effects of (-)-noradrenaline. On the other hand, electric field stimulation of the complete mucosa containing urothelium together with lamina propria causes neurogenic contractions that do not involve muscarinic, adrenergic, purinergic, or neurokinin neurotransmission [23].

\section{Effects of Drugs on KCl-and Carbachol-Induced Contraction}

Human detrusor preparations were activated either by depolarization with $\mathrm{KCl}$ and subsequent $\mathrm{Ca}^{2+}$ influx via activated voltage-dependent calcium channels or by stimulation of muscarinic receptors with the parasympathomimetic agent carbachol [24]. Although the major goal of our present study was to identify signal transduction pathways that may contribute to the mucosa effect of catecholamine-induced detrusor relaxation, the experiments also provided confirmation about the drug effects on the 2 modes of precontractions. Such comparison with published data seemed useful in view of some conflicting results, as for instance, whether the urothelium affects $\mathrm{KCl}$-activated contractions [7] vs. [9], see Introduction.

\section{Role of NO}

Reduction of endogenous NO production by unselective inhibition of NO synthases with L-NAME strongly enhanced $\mathrm{KCl}$-induced contraction, independent of the presence or the absence of urothelium. There was also a tendency to higher force development in response to carbachol, but this difference did not reach statistical significance. These results suggest that endogenous NO may attenuate the level of stimulated tension development [3] and confirm that NO is probably not the urothelium-de- rived relaxing factor $[4,25,26]$. Moreover, $\mathrm{NO}$ is unlikely to be involved in noradrenaline-induced relaxation because L-NAME had no effect on the concentration-relaxation curves with or without urothelium. This result is in good agreement with lack of NO effects on urotheliumdependent relaxation in isoprenaline-induced relaxation [14].

\section{Role of ATP and Endothelin}

Block of the P2X purinoreceptor with PPADS or of the endothelin receptors $\mathrm{ET}_{\mathrm{A}}$ and $\mathrm{ET}_{\mathrm{B}}$ with $\mathrm{BQ}-123$ and $\mathrm{BQ}$ 788 had no effect on KCl- or carbachol-stimulated contraction and did not modulate the difference in contractions with and without urothelium. We observed some desensitization to noradrenaline-induced relaxation in denuded $\mathrm{KCl}$ - but not in carbachol-precontracted muscles with PPADS and in denuded muscles (either of the precontraction mode) with BQ-123 plus BQ-788. Therefore, we conclude that the role of purinergic compounds or endothelin is probably minor.

\section{Role of Prostaglandins}

Prostanoids are released in the human urinary bladder [27], many of which contract human detrusor muscles $[28,29]$. Suppression of prostaglandin synthesis by diclofenac influenced neither KCl- nor carbachol-contractions in denuded muscles suggesting that prostaglandin release does not contribute to these 2 modes of stimulation. The finding, that diclofenac enhanced, rather than reduced, force induced in intact muscle by $\mathrm{KCl}$ but not by carbachol is difficult to interpret. We speculate that $\mathrm{KCl}$ may release another counteracting factor from the urothelium. Alternatively, a relaxing prostaglandin, such as $\mathrm{PGD}_{2}$, is no longer produced in active concentrations [26]. Clearly, prostaglandins are involved in reducing the sensitivity of the intact and denuded detrusor to noradrenaline-induced relaxation, because diclofenac shifted the concentration-response curve to lower concentrations and enhanced efficacy in intact strips. Further experiments are required to elucidate the prostaglandins and the receptor subtypes that may be involved.

\section{Role of Angiotensin}

Angiotensin-II is known to contract detrusor muscle [3]. The lower urinary tract harbors a local renin-angiotensin system [30] that contributes to stress incontinence in animal models [31]. A post hoc analysis of antihypertensive patients treated with $\mathrm{AT}_{1}$ receptor blockers revealed lesser lower urinary tract symptoms than the untreated subjects [32]. Here, we have demonstrated 
that blocking $\mathrm{AT}_{1}$ receptors sensitizes denuded and intact human detrusor to noradrenaline relaxation suggesting that local angiotensin II production counteracts smooth muscle relaxation by noradrenalin and is also involved in blunting the noradrenaline relaxation in the presence of urothelium. The effects were more pronounced in carbachol- than in $\mathrm{KCl}$-precontracted preparations. We speculate that by promoting catecholamine-induced relaxation, $\mathrm{AT}_{1}$ receptor blockers may be of therapeutic benefit in the overactivity of the lower urinary tract.

\section{Role of Neurokinin}

Tachykinins activated NK receptors that mediate detrusor contraction [3]. Block of $\mathrm{NK}_{1}$ receptors significantly enhanced carbachol responses in intact but not in denuded detrusor. Similar to our arguments for diclofenac, this could hint at tachykinin-induced release of a contraction counteracting factor. In the presence of the $\mathrm{NK}_{1}$ blocker, L-703,606, modulation of noradrenaline relaxation was only observed in the presence of urothelium including tachykinins as a putative compound involved in 'urothelium-derived contracting factor'.

\section{Study Limitations}

The different receptors involved in the relaxing effect of catecholamines in human detrusor could also be altered by pathology. For instance, $\beta_{3}$-ARs might be overexpressed in obstructed or diseased human bladder [33]. However, this issue cannot be resolved because detrusor tissue from healthy human probands is not available.

\section{Conclusion}

The mucosa of human detrusor strips impairs noradrenaline-induced relaxation, and this effect is attenuated by diclofenac, candesartan and L-703,606 suggesting the involvement of prostanoids, as well as $\mathrm{AT}_{1}$ and $\mathrm{NK}_{1}$ receptors.

\section{Acknowledgments}

We thank Maria Feilmeier, Romy Kempe and Manja Newe for their excellent technical help.

\section{References}

$>1$ Kosilov KV, Loparev SA, Ivanovskaya MA, Kosilova LV: Comparative effectiveness of combined low- and standard-dose trospium and solifenacin for moderate overactive bladder symptoms in elderly men and women. Urol Int 2014;93:470-473.

-2 Chapple C, Khullar V, Nitti VW, Frankel J, Herschorn S, Kaper M, Blauwet MB, Siddiqui E: Efficacy of the $\beta 3$-adrenoceptor agonist mirabegron for the treatment of overactive bladder by severity of incontinence at baseline: a post hoc analysis of pooled data from three randomised phase 3 trials. Eur Urol 2015;67:11-14.

-3 Andersson KE, Arner A: Urinary bladder contraction and relaxation: physiology and pathophysiology. Physiol Rev 2004;84:935986.

$\checkmark 4$ Hawthorn MH, Chapple CR, Cock M, ChessWilliams R: Urothelium-derived inhibitory factor(s) influences on detrusor muscle contractility in vitro. Br J Pharmacol 2000;129: 416-419.

5 Masunaga K, Chapple CR, McKay NG, Yoshida M, Sellers DJ: The $\beta 3$-adrenoceptor mediates the inhibitory effects of $\beta$-adrenoceptor agonists via the urothelium in pig bladder dome. Neurourol Urodyn 2010;29:13201325.

-6 Propping S, Wuest M, Eichhorn B, Wirth MP, Kaumann AJ, Ravens U: Mucosa of human detrusor impairs contraction and $\beta$-adrenocep- tor-mediated relaxation. BJU Int 2013;112: 1215-1222.

7 Wuest M, Kaden S, Hakenberg OW, Wirth MP, Ravens U: Effect of rilmakalim on detrusor contraction in the presence and absence of urothelium. Naunyn Schmiedebergs Arch Pharmacol 2005;372:203-212.

8 Maggi CA, Santicioli P, Parlani M, Astolfi M, Patacchini R, Meli A: The presence of mucosa reduces the contractile response of the guinea-pig urinary bladder to substance P. J Pharm Pharmacol 1987;39:653-655.

$\checkmark 9$ Chaiyaprasithi B, Mang CF, Kilbinger H, Hohenfellner M: Inhibition of human detrusor contraction by a urothelium derived factor. J Urol 2003;170:1897-1900.

$>10$ Levin RM, Wein AJ, Krasnopolsky L, Atta MA, Ghoniem GM: Effect of mucosal removal on the response of the feline bladder to pharmacological stimulation. J Urol 1995; 153:1291-1294.

11 Morita T, Iizuka H, Iwata T, Kondo S: Function and distribution of beta3-adrenoceptors in rat, rabbit and human urinary bladder and external urethral sphincter. J Smooth Muscle Res 2000;36:21-32.

12 Yamanishi T, Chapple CR, Yasuda K, Yoshida K, Chess-Williams R: The role of beta(3)adrenoceptors in mediating relaxation of porcine detrusor muscle. Br J Pharmacol 2002; 135:129-134.
13 Murakami S, Chapple CR, Akino H, Sellers DJ, Chess-Williams R: The role of the urothelium in mediating bladder responses to isoprenaline. BJU Int 2007;99:669-673.

14 Otsuka A, Shinbo H, Matsumoto R, Kurita Y, Ozono S: Expression and functional role of beta-adrenoceptors in the human urinary bladder urothelium. Naunyn Schmiedebergs Arch Pharmacol 2008;377:473481.

15 Wuest M, Eichhorn B, Grimm MO, Wirth MP, Ravens U, Kaumann AJ: Catecholamines relax detrusor through beta 2 -adrenoceptors in mouse and beta 3-adrenoceptors in man. J Pharmacol Exp Ther 2009;328: 213-222.

16 Propping S, Newe M, Lorenz K, Wirth MP, Ravens U: $\beta$-Adrenoceptor-mediated relaxation of carbachol-pre-contracted mouse detrusor. Urol Int 2015, Epub ahead of print.

-17 Yoshida M, Masunaga K, Satoji Y, Maeda Y, Nagata T, Inadome A: Basic and clinical aspects of non-neuronal acetylcholine: expression of non-neuronal acetylcholine in urothelium and its clinical significance. J Pharmacol Sci 2008;106:193-198.

18 Ferguson DR, Kennedy I, Burton TJ: ATP is released from rabbit urinary bladder epithelial cells by hydrostatic pressure changes - a possible sensory mechanism? J Physiol 1997; 505:503-511.
Pharmacological Modulation of Mucosa-Related Impairment 
19 Lecci A, Maggi CA: Tachykinins as modulators of the micturition reflex in the central and peripheral nervous system. Regul Pept 2001; 101:1-18.

20 Khan MA, Thompson CS, Mumtaz FH, Jeremy JY, Morgan RJ, Mikhailidis DP: Role of prostaglandins in the urinary bladder: an update. Prostaglandins Leukot Essent Fatty Acids 1998;59:415-422.

21 Arrighi N, Bodei S, Lucente A, Michel MC, Zani D, Simeone C, Cunico SC, Spano P, Sigala S: Muscarinic receptors stimulate cell proliferation in the human urothelium-derived cell line UROtsa. Pharmacol Res 2011;64:420-425.

-22 Ochodnický P, Humphreys S, Eccles R, Poljakovic M, Wiklund P, Michel MC: Expression profiling of g-protein-coupled receptors in human urothelium and related cell lines. BJU Int 2012;110:E293-E300.

23 Moro C, Chess-Williams R: Non-adrenergic, non-cholinergic, non-purinergic contractions of the urothelium/lamina propria of the pig bladder. Auton Autacoid Pharmacol 2012; 32:53-59.
24 Sui GP, Wu C, Fry CH: A description of ca2+ channels in human detrusor smooth muscle. BJU Int 2003;92:476-482.

25 Guan NN, Thor A, Hallén K, Wiklund NP, Gustafsson LE: Cascade bioassay evidence for the existence of urothelium-derived inhibitory factor in guinea pig urinary bladder. PLoS One 2014;9:e103932.

26 Guan NN, Nilsson KF, Wiklund PN, Gustafsson LE: Release and inhibitory effects of prostaglandin D2 in guinea pig urinary bladder and the role of urothelium. Biochim Biophys Acta 2014; 1840:3443-3451.

27 Jeremy JY, Dandona P: Fluoride but not phorbol esters stimulate rat urinary bladder prostanoid synthesis: investigations into the roles of $\mathrm{G}$ proteins and protein kinase $\mathrm{C}$. Prostaglandins Leukot Med 1987;29:129139.

28 Anderson KE: Pharmacology of lower urinary tract smooth muscles and penile erectile tissues. Pharmacol Rev 1993;45:253-308.
9 Rahnama'i MS, van Kerrebroeck PE, de Wachter SG, van Koeveringe GA: The role of prostanoids in urinary bladder physiology. Nat Rev Urol 2012;9:283-290.

30 Comiter C, Phull HS: Angiotensin II type 1 (AT-1) receptor inhibition partially prevents the urodynamic and detrusor changes associated with bladder outlet obstruction: a mouse model. BJU Int 2012;109:1841-1846.

31 Phull H, Salkini M, Escobar C, Purves T, Comiter CV: The role of angiotensin II in stress urinary incontinence: a rat model. Neurourol Urodyn 2007;26:81-88; discussion 89.

32 Ito $\mathrm{H}$, Taga $\mathrm{M}$, Tsuchiyama K, Akino $\mathrm{H}$, Yokoyama O: IPSS is lower in hypertensive patients treated with angiotensin-II receptor blocker: posthoc analyses of a lower urinary tract symptoms population. Neurourol Urodyn 2013;32:70-74.

3 Nomiya M, Yamaguchi O: A quantitative analysis of mRNA expression of alpha 1 and beta-adrenoceptor subtypes and their functional roles in human normal and obstructed bladders. J Urol 2003;170:649-653. 